\title{
Off-pump coronary bypass grafting: the new gold standard!
}

\author{
Kamales Kumar Saha ${ }^{1}$
}

Received: 11 August 2017 /Revised: 29 August 2017 / Accepted: 5 September 2017 / Published online: 2 October 2017

(C) Indian Association of Cardiovascular-Thoracic Surgeons 2017

Off-pump coronary artery bypass (OPCAB) surgery is an evolution in the field of cardiac surgery which helped keep up with rapid technological advances in the field of percutaneous coronary intervention (PCI). In spite of the cardiologist being the "gate keeper" for referring patients for PCI or surgery, preference for $\mathrm{OPCAB}$ has grown over on-pump coronary artery bypass grafting surgery $(\mathrm{ONCAB})$. The advantages of $\mathrm{OPCAB}$ over $\mathrm{ONCAB}$ can be debated and the final verdict is yet to come [1]. In India OPCAB has become the preferred mode of revascularization in private health care system. This is because surgeons who are efficient in OPCAB often migrate to private hospitals for better compensation. Private hospitals use proficiency in OPCAB as one of the major criteria for selecting surgeons. The polarization is complete in private sector in favor of OPCAB. Cardiologists are the end result assessor of both procedures. In spite of the obvious conflict of interest, OPCAB remains the preferred mode of revascularization over both PCI and ONCAB.

However, in western world the situation is different probably because healthcare is funded by either insurer or tax-payer. The patient prefers the less invasive procedure even though it may not necessarily be the treatment with best long-term result. The insured patient is not deterred by the possibility of a costly second procedure after PCI. That is why major hindrance to development of OPCAB in western world is

Meeting presentation: None

Kamales Kumar Saha

kamalessk@gmail.com

1 Private Practice, Multiple Private Hospitals, C801/802 Raheja Sherwood, Behind HubMall, Western Express Highway, Goregaon East, Mumbai 400063, India probably the stent industry. If superiority of OPCAB is established, stent industry will incur huge revenue loss. Any trial publishing inferior OPCAB results is often highlighted in western literature. All trials comparing coronary artery bypass grafting $(\mathrm{CABG})$ and $\mathrm{PCI}$ have proven that stroke is the Achilles' heel of CABG. OPCAB with aortic no touch can eliminate this disparity. It is not surprising that no single trial is designed to compare OPCAB with aortic no touch to multivessel PCI. Even arterial revascularisation therapy study (ARTS) had only $40 \%$ OPCAB patients [2].

In spite of growing popularity there are few OPCAB publications from India. There are various factors for lack of Indian publications:

Reluctant to publish: Surgeons with good results are often reluctant to publish. With experience, we learn many tricks, and unless we share with the future generation, these tricks will not survive. By publishing our technique and results, we can share our experience beyond geographical borders.

Inadequate prospective data collection: Prospective data collection is often neglected in our country across all centers. Case papers are destroyed after 5 years, the mandatory period by law. Prospective collection of preoperative and postoperative data is required. We need to move to electronic record keeping so that the collected data can be preserved, accessed, and analyzed. We can only publish superior OPCAB results if we have access to properly collected patient data.

Lack of regular self audit: Regular self audit is mandatory for quality improvement. Sometimes regular self audit can lead to results which will contradict convention. Routine surgical audit had detected that Nicorandil infusion during OPCAB may improve hemodynamic stability particularly in patients with left 
ventricular dysfunction. Later, the data was analyzed, presented, and published [3].

Practical problems of publication: Lack of credible Indian published data is a major deterrent. Renowned journals in the field of cardiac surgery with the highest impact factor have a non-blinded review system. Often, reviewer bias comes into play. There are few Indian journals, with limited space, where we can publish our work. Lack of time bound review adds to the hindrance. We should have a strong positive bias to publish Indian studies in our journals even if an article demands extensive revision. Reviewing is an important but thankless job. Reviewer reward in the form of recognition in the annual conference will probably encourage reviewers to submit their opinion quickly and may help to reduce reviewing time. Personal views are often quoted in scientific studies with quotes "in our opinion" or "in our experience," which lead to rejection of articles. These types of comments are best avoided. Underestimating own work is common practice and should be avoided.

\section{OPCAB: the future of surgical coronary revascularization}

Advantages of avoiding cardiopulmonary bypass (CPB) are well established $[1,4]$. In the current era there are two major areas of concern which prevent universal acceptance of $\mathrm{OPCAB}$ technique: complete revascularization and early graft patency.

Complete revascularization It is now well established that complete revascularization can be performed easily using $\mathrm{OPCAB}$ technique without any concern of increasing CPB time or ischemic time [4]. Many studies published in international literature confirm this [4]. In a series of more than 600 consecutive unselected Indian patients, it was proven that complete revascularization can be better performed using OPCAB technique in spite of diffuse coronary artery disease (CAD), low ejection fraction or recent myocardial infarction without the anxiety of increasing cardiopulmonary bypass time or ischemic time [5]. Similar experience is reported from other centers with dedicated OPCAB surgeons [6].

Early graft patency Early graft patency rate is another area of concern of OPCAB technique. In absence of published data on OPCAB graft patency, proponents of OPCAB have to rely on personal or shared experiences. This important issue of OPCAB graft patency is addressed in a study published in this journal [7]. I congratulate the authors for this study which proves that OPCAB results in our country can be far superior to randomized controlled trials (RCT) published in western world. International randomized funded study like Randomized On/Off Bypass trial (ROOBY) trial had 62\% follow-up angiogram. Danish On-pump versus Off-pump Randomization study (DOORS) had 50\% angiogram in ONCAB and $57 \%$ in OPCAB group. Considering that the authors did not have any funding, $44.5 \%$ follow-up Computerised Tomography (CT) angiography is a strong point of the study. It is very difficult to convince an asymptomatic patient to undergo a test and more so if they have to pay for it. OPCAB graft patency rates of Left Internal Mammary Artery (98.3\%), Radial Artery (96\%) and Saphenous Vein (91.2\%) published in this study are excellent and far superior than both ONCAB and OPCAB graft patency rates of the recently published RCTs from the western world. The beneficial effects of dual anti-platelet therapy on OPCAB graft patency have been discussed in literature [4] and in this study too, Raghuram et al. rightly used dual antiplatelet therapy immediately after OPCAB. However, I disagree with their viewpoint that maintaining activated clotting time (ACT) more than 350 seconds during OPCAB is mandatory. In a study from Korea, ACT level more than 350 seconds during OPCAB resulted in paradoxically higher incidence of perioperative myocardial infarction. Higher level of anticoagulation during OPCAB may result in paradoxical platelet activation which may lead to early graft failure [8]. Lower ACT level during $\mathrm{OPCAB}$ is safe, decreases blood loss and may improve vein graft patency [8].

I would take this opportunity to request all surgeons in our country to publish their OPCAB experience. If we publish our results of OPCAB more frequently, superiority of OPCAB can be easily established. Graft patency after $\mathrm{CABG}$ is multi-factorial and partly dependent on surgical dexterity. While $\mathrm{CABG}$ on still heart is easy to teach, OPCAB will require patience, commitment, dedication and self belief. OPCAB can be performed in every situation where isolated $\mathrm{CABG}$ is indicated. ONCAB should be reserved for combined procedures (e.g. valve surgery with $\mathrm{CABG}$ ), rare case of intracavitory coronary artery which requires grafting and intractable arrhythmias during $\mathrm{OPCAB}$ even after intra-aortic balloon pump insertion. OPCAB gives us the opportunity to perform complete revascularization with minimal morbidity and excellent graft patency. It is time for us to admit that off-pump coronary artery bypass grafting is the new gold standard in surgical coronary revascularization.

Compliance with ethical standards

Disclosure None. 


\section{References}

1. Yadava OP, Kundu A. "On" or "off" pump coronary artery bypass grafting —is the last word out? Indian Heart J. 2013;65:187-90.

2. Taggart DP, Altman DG, Gray AM, et al. Effects of on-pump and offpump surgery in the arterial revascularization trial. Eur J Cardiothorac Surg. 2015;47:1059-65.

3. Saha KK, Kumar A, Deval MM, et al. Nicorandil infusion during off-pump coronary artery bypass grafting reduces incidence of intraaortic balloon pump insertion. Innovations. 2016;11:123-7.

4. Saha KK. Off-pump coronary artery bypass grafting in India. Indian Heart J. 2014;66:203-7.
5. Saha KK, Deval MM, Kumar A, et al. Off-pump bilateral internal thoracic artery grafting. Heart Lung Circ. 2015;24: 905-11.

6. Raja SG. Two decades of off-pump coronary artery bypass surgery: Harefield experience. J Thorac Dis. 2016;8:S824-8.

7. Raghuram ARR, Subramanyan K, Sivakumaran S, Chandrasekar P, Harikrishnan S, Arunkumar G. Graft patency study in off-pump coronary artery bypass surgery. Indian J Thorac Cardiovasc Surg. 2017; https://doi.org/10.1007/s12055-017-0587-x.

8. Saha KK, Sangwan DK, Shroff PK, et al. Off-pump coronary artery bypass grafting using continuous heparin infusion. Indian Heart J. 2016;68:798-802. 